\title{
A Tribute to Dr. Christopher G. Wood, MD
}

Dr. Nizar M. Tannir, MD, FACP, MD Anderson Cancer Center, Houston, TX

\author{
https://doi.org/10.52733/KCJ19n4-t
}

$\mathrm{T}$

ributes to individuals who have passed away share one common purpose: to help us heal. We find comfort by sharing the legacies of the loved ones we've lost. Today we pay tribute to Dr. Christopher G. Wood, Professor of Urology.

Dr. Wood passed away at home after a brief illness on November 3, 2021. Chris had a sharp mind, a keen wit and wonderful sense of humor, but above all, he possessed a love for the medical profession, serving his patients and training urology fellows. He is remembered by his colleagues as a surgeon with the highest ethical standards, a selfless mentor dedicated to the training of his fellows and sponsoring them for academic careers in urological oncology.

Dr. Wood came to MD Anderson as a urology oncology fellow in 1995 and joined the faculty three years later with a dual appointment as Assistant Professor in Urology and Cancer Biology. He was promoted to Full Professor with Tenure in 2010 and received the Douglas E. Johnson, M.D., Endowed Professorship in Urology in 2012. He served as Deputy Chair of the Department of Urology from 2008 until few months before his death. He operated three days per week and saw more than 50 patients in his clinic one day a week.

During his 26 years at MD Anderson, Dr. Wood operated on more than seven thousand patients and performed radical and partial nephrectomies on five thousand patients. He operated successfully on patients with large, locally

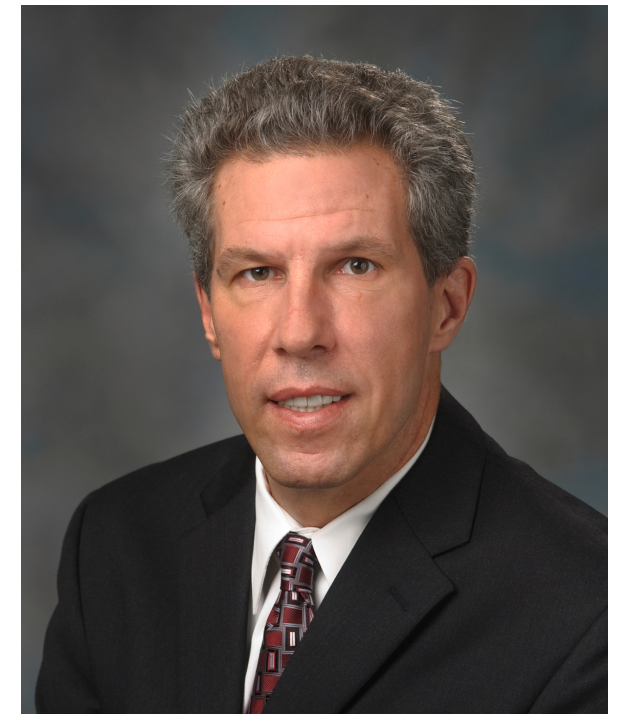

November 22, 1963 - November 3, 2021

\section{"Dr. Chris Wood was larger than life} and leaves a shining legacy that includes a new generation of urologists whom he educated, trained, mentored, and sponsored and the thousands of lives he saved." advanced renal tumors that other urologists could not remove. Karen Ronquillo, the widow of John Ronquillo whom both Chris and I treated and cared for, described Wood as "the doctor with the confident handshake and warm smile who accepted cases others had written off. Dr. Wood blessed our family by extending my husband's life with a risky, lengthy surgery his local surgeon would not consider."

Chris was considered a legend in the operating room. "He could do things in 40 minutes that other surgeons needed three hours to complete, and he did it better than they ever could do," said Associate Professor Neema Navai, one of Chris' former mentees.

Wood was passionate about education and served as his department CME course chair. He chaired the annual MD Anderson Urology Oncology Conference for 15 years. As part of the renal cell carcinoma (RCC) program, he always included a session in which he'd present challenging cases to a panel of expert urologists and medical oncologists. Then, he'd famously remark, "Don't tell me what you could do, or others would do; tell me what you would do in this case." The "Wood Fire session", as it was known, would become his trademark and a tradition highlighted and looked forward to at the annual International Kidney Cancer symposium (IKCS). 
Throughout his tenure at MD Anderson, Dr. Wood was devoted to developing and sponsoring his fellows, who became known as the "Wood Fellows". "Your success is my success," he often told his mentees. Chris's commitment to his fellows' success was described as "unconditional generosity," by Jose Karam whom Wood recruited to join the faculty of the Urology Department after completing his fellowship under him. Scott Delacroix, a former Wood fellow and now director of urologic oncology at LSU, called his mentor a role model, noting his unparalleled surgical skills and "unwavering support" for his fellows. But beyond that, Delacroix said, "Even with the successes in the field, Chris Wood's most admirable trait was his ability to still be a real down to earth person, devoid of the ego that is all too common in those considered some of the world's best." That sentiment was echoed by Brian Chapin, Associate Professor of Urology at MD Anderson, also a former Wood fellow. "One of the things I admire most about him was his ability to put his own ego aside and elevate others around him."

During his illustrious career, Dr. Wood trained more than 75 urology fellows while serving as director of clinical research in his department for 15 years. But his devotion to education extended beyond the walls of MD Anderson. Dr. Wood committed much of his personal time and energy to the Kidney Cancer Association (KCA). He chaired the annual patient conference every spring for more than 15 years and, for the past six years and until his death, he served as chairman of the KCA Board of Directors. "We'd talk multiple times a week, almost every day. He was such a wonderful sounding board and even better friend. I've literally never known someone so genuinely themselves with no agenda, no ego, who always made me feel like I was enough. He was always unconditional," said Gretchen Vaughan, President and CEO of KCA.

Dr. Wood made significant research contributions to the field of kidney cancer. He pioneered the integration of systemic therapy and cytoreductive nephrectomy in patients with metastatic RCC and neoadjuvant targeted therapy in patients with locally advanced RCC. His laboratory was successful in generating several RCC cell lines and patient derived xenografts, including rare variant types such as translocation RCC and renal medullary carcinoma, which have been used for target discovery and testing novel therapeutics in co-clinical trials. His productive clinical and translational research was published in more than 350 manuscripts. Additionally, he contributed 28 chapters to books on kidney cancer and was honored with more than 40 visiting professorships in the U.S. and abroad.

For the past 20 years, I had the privilege to care for hundreds of patients with RCC who were referred to me by Dr. Wood, and I, in turn, referred hundreds of patients to him for cytoreductive nephrectomies. I thought and hoped our professional partnership would continue until we both retired from MD Anderson.

Our lives were intertwined. My PA for 17 years Zita Dubauskas Lim, his nurse for 22 years Jan Jackson, and his PA for 13 years Reena Cherry, referred to us as 'Ying and Yang'. I respected Dr. Wood for his surgical skills and judgment and admired his unwavering devotion to and advocacy for his patients. He never said "no" to overbooking a new patient in his clinic. We never argued about the management of a patient, which is rare for a medical doctor and a surgeon. I trusted his surgical skills to operate on the most complex cases, and he trusted my judgment on the management of patients with metastatic disease and the implementation of therapies when indicated.

Once, I told Chris that I realized why we were destined to be BFF. He was amused to learn that he was born the same year as my younger brother and shared my daughter's birthday. This past November 22nd, I celebrated my daughter's seventeenth birthday with her, but I felt a big hole in my heart. Chris's untimely death came on the eve of the 17th IKCS, which he had hoped to attend in Austin despite his failing legs and eyesight.

Dr. Wood passed away 19 days before his 58th birthday. Chris was a loving husband to his wife Colleen and a devoted father to Chris, Jr. and Sarah. He is sorely missed by his family, friends, colleagues, mentees, his longtime administrative assistant and coordinator, his clinic and research staff, and all the people who loved him.

Dr. Chris Wood was larger than life and leaves a shining legacy that includes a new generation of urologists whom he educated, trained, mentored, and sponsored and the thousands of lives he saved. Many of us believe it may take generations to see his equal again. 